\title{
$\nabla$
}

\section{Clinical and histological challenge in the differential diagnosis of diffuse alopecia: female androgenetic alopecia, telogen effluvium and alopecia areata - Part I \\ Desafio clínico e histológico no diagnóstico diferencial de alopecia difusa: alopecia androgenética, eflúvio telógeno e alopecia areata - Parte I}

\author{
Betina Werner ${ }^{1}$
}

\author{
Fabiane Mulinari-Brenner ${ }^{2}$
}

\begin{abstract}
Diffuse androgenetic alopecia (female pattern hair loss), telogen effluvium, and diffuse alopecia areata may have similar clinical manifestations. Subtle details on physical examination and dermoscopy of the scalp may help to identify those disorders. The authors present a practical discussion on how to approach the patient with diffuse alopecia, considering clinical history, physical examination, and dermoscopic findings. If the diagnosis remains unclear after a careful analysis of the clinical signs, a scalp biopsy may help to distinguish between the three diseases. In this first part of our study, an objective review of female androgenetic alopecia is presented and the most important histological changes are discussed.
\end{abstract}

Keywords: Alopecia; Alopecia areata; Biopsy; Dermoscopy

\begin{abstract}
Resumo: Alopecia androgenética difusa (alopecia de padrão feminino), eflúvio telógeno e alopecia areata difusa podem ter apresentações clínicas similares. Detalhes sutis no exame físico e na dermatoscopia do couro cabeludo podem ser úteis no diagnóstico diferencial e interferir na conduta e resultados terapêuticos. Os autores apresentam uma discussão prática de como abordar a paciente com alopecia difusa considerando dados da história clínica, exame físico e dermatoscópico. Quando a dúvida persistir após uma análise cuidadosa dos aspectos clínicos, uma biópsia de couro cabeludo pode permitir a distinção entre as três doenças. Nesta primeira parte, a alopecia androgenética de padrão feminino é abordada em maior detalhe e se faz uma revisão objetiva das principais alterações microscópicas observadas.
\end{abstract}

Palavras-chave: Alopecia; Alopecia em áreas; Biópsia; Dermoscopia

\footnotetext{
Received on 09.03.2011.

Approved by the Advisory Board and accepted for publication on 25.04.2011.

* Work conducted at the Pathology and Dermatology Service, Clinics Hospital (Hospital de Clínicas), Federal University of Parana (HC-UFPR), Diagnose (private practice of Surgical Pathology and Dermatopathology), and Cepelle (Center Specialized in the Skin - private practice of Dermatology) - Curitiba (PR), Brazil. Conflict of interest: None

Financial funding: None

PhD - Dermatopathologist with a diploma from the International Society of Dermatopathology - MSc in Clinical Surgery (with concentration in Surgical Pathology), Federal University of Parana (UFPR). PhD in Child and Adolescent Health (with concentration in Dermatopathology), Federal University of Parana (UFPR) - Professor at the Department of Pathology - Clinics Hospital (Hospital de Clínicas), Federal University of Parana (HC-UFPR) - Curitiba (PR) Brazil.

MSc - Dermatologist. MSc in Internal Medicine, Federal University of Parana (UFPR). Professor of Dermatology, Clinics Hospital (Hospital de Clínicas), Federal University of Parana (HC-UFPR) - Curitiba (PR), Brazil. 


\section{INTRODUCTION}

Diffuse alopecia is defined as global diminishing of hair with no formation of areas completely bald. ${ }^{1}$ Diffuse hair loss, especially in women, is a common complaint in dermatology practice. The congenital forms of diffuse alopecia and anagen effluvium after chemotherapy generally present strong diagnostic signs. However, telogen effluvium, androgenetic alopecia and diffuse alopecia areata are common disorders that present a challenge in the differential diagnosis. In typical situations it is not difficult to diagnose these disorders. However, these three forms of alopecia may have similar clinical signs in the following situations: when telogen effluvium does not occur in an acute way two to three months after a known triggering factor; when the androgenetic alopecia is at its initial stage or with female androgenetic alopecia pattern; or when alopecia areata does not present welldefined bald areas. In these cases, subtle details will help distinguish one disorder from the other. ${ }^{1,2,3}$

This article, which is divided into two parts, aims to highlight the most relevant clinical, dermoscopic, and histological differences between female androgenetic alopecia, telogen effluvium, and diffuse alopecia areata in a practical and objective way to help the dermatologist to diagnose the causes of diffuse alopecia. Detailed information about each disorder can be found in literature reviews. ${ }^{2-12}$

In this first part, the authors discuss the clinical, dermoscopic, and histological findings of diffuse alopecia in general as well as those of female androgenetic alopecia. In the second part, the authors discuss telogen effluvium and diffuse alopecia and compare the three disorders in an objective way, presenting them in a flowchart.

\section{MEDICAL HISTORY, PHYSICAL EXAMINATION AND LABORATORY CHANGES \\ Diffuse alopecia}

Women are more susceptible to telogen effluvium, more affected by central-pattern androgenetic alopecia, and the main affected ones in most descriptions of diffuse alopecia areata. ${ }^{13-15}$ Female-pattern baldness seems to be the most frequent form of diffuse alopecia, followed by telogen effluvium. Prevalence of diffuse alopecia areata is still unknown, probably due to underdiagnosis. ${ }^{13,14}$ Duration of the disorder, type of complaint, and affected area of the scalp are determined during the medical interview. Possible triggers and time interval between these events and the onset of complaints can assist in investigating the etiology, as well as the identification of associated diseases. Diet, medication being taken and dosages should be investigated. Careful examination of the scalp, parting the hair from the frontal hairline to the occipital area, is a good way to find changes in hair density; a magnifying glass or dermoscopy can assist in the examination (Figure 1). ${ }^{16}$ The light hair pull test, the pluck test, analysis of hair spontaneously shed, and trichogram can be critical. No laboratory investigation is essential for the diagnosis of diffuse alopecia.

\section{Female androgenetic alopecia}

Androgenetic alopecia in its diffuse form is preferably called female androgenetic alopecia. Most often, it affects women and does not present hyperandrogenemia in most cases. Female androgenetic alopecia occurs only after puberty. The main complaint is thinning of the hair. Actual hair loss may occur in the early stages, but the inability to recover hair density is

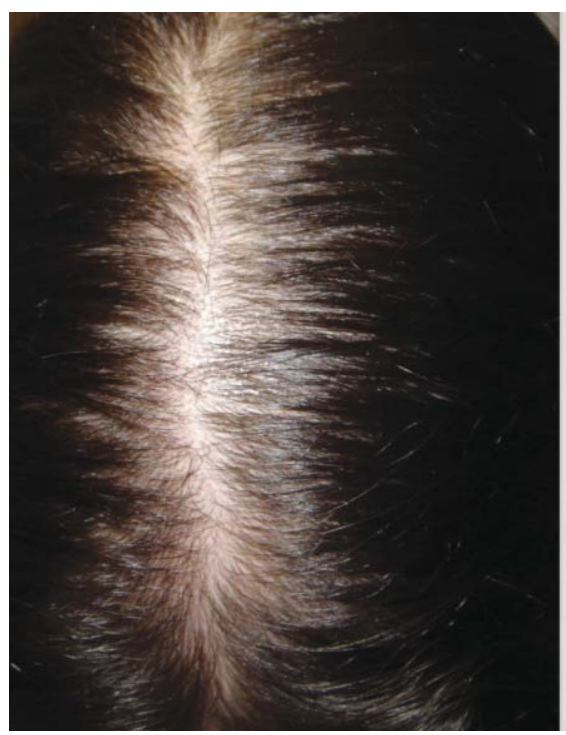

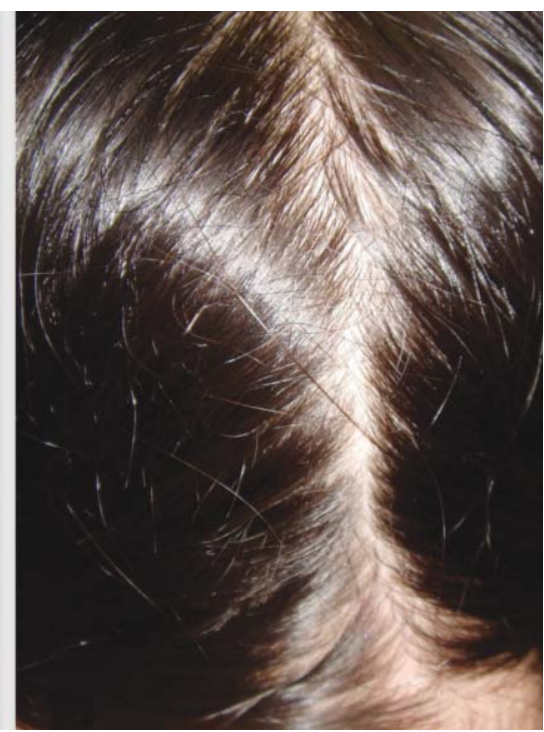

Figure 1: Physical examination. A. Central parting, aspect of the crown of the scalp. $\mathbf{B}$. Central parting, aspect of the occipital scalp 
characteristic. Clinically, hair loss is progressive in the upper part of the scalp, and the frontal hairline is maintained (Figure 2). In general, patients get to their twenties and forties complaining of thinner hair and "visible" scalp. Genetic inheritance is variable in female androgenetic alopecia. There are many genes involved in it, and their participation is not yet well defined. ${ }^{15}$ Again, women are more affected by this pattern of alopecia, which causes great psychological disturbance. ${ }^{17}$ Occasionally, men may present with female androgenetic alopecia without lacking hair in the front of the scalp, which is characteristic of males. ${ }^{15}$ Prevalence of female androgenetic alopecia increases with age: $12 \%$ of women in their twenties, $25 \%$ in their fifties, and $50 \%$ in their eighties. ${ }^{18}$ Thickness of the hair shaft is progressively reduced, defining the mechanism of follicular miniaturization in the central area of the scalp. As the hair is parted, one can easily observe hair thinning, even in the initial phases of the condition. A higher concentration of aromatase in the occipital area of men and women and in women's frontal hairline is capable of converting strong androgens, like testosterone, into estradiol and estrone, avoiding miniaturization. ${ }^{19}$

Another important change occurs in the follicular cycle. In women with female androgenetic alopecia, it was observed that $80 \%$ of the follicles had a real rest period at the end of the telogen phase. This period lasted from three to twelve months in $22 \%$ of the follicles, contributing to a decrease in hair density. ${ }^{20}$ This phase, called teloptosis or kenogen, is responsible for empty follicles visualized on physical examination and dermoscopy.

Associations with acne, hirsutism, acanthosis nigricans, infertility, and obesity may occur as part of hyperandrogenic syndromes, especially polycystic ovary syndrome and metabolic syndrome. ${ }^{21}$ The criteria for diagnosis of polycystic ovary syndrome can be observed in up to $47 \%$ of patients with female androgenetic alopecia, and the criteria for diagnosis of anatomical ovarian polycystosis can be observed in up to $67 \%$ of these patients. ${ }^{22}$ Hyperinsulinemia and obesity decrease the amount of sex-hormone-binding globulin (SHBG), increasing ovarian production of androgens and, thus, aggravating hair thinning. ${ }^{21}$ Monophasic contraceptives, implants with progestogens, and androgen supplements may trigger or worsen this kind of alopecia. The light hair pull test is generally negative, and the amount of daily hair loss is normal, up to 100 telogen hairs/day. A microscopic evaluation of spontaneously-shed hairs collected over a day exclusively reveals telogen hairs with shafts of different diameters, associated with miniaturization.

Among the patients with female androgenetic alopecia, those with menstrual irregularities or signs of hyperandrogenism should be subjected to a simple laboratory investigation, since less than $40 \%$ of them present changes in plasma androgens. ${ }^{22}$ Dosages of luteinizing hormone (LH) and follicle-stimulating hormone (FSH), associated to the levels of dehydroepiandrosterone sulfate (DHEAS) and total testosterone, assess ovarian function, adrenal function, and extra production of androgens, respectively, and appear to be sufficient. The extensive investigation of hyperandrogenism does not change therapy in most cases. ${ }^{22}$ Moreover, ferritin levels below $40 \mathrm{ng} / \mathrm{dl}$ were found in $72 \%$ of women with female androgenetic alopecia. ${ }^{22}$ Despite the uncertain significance of this finding, it might explain why outbreaks of telogen effluvium are more common in women than in men with androgenetic alopecia. ${ }^{22}$

\section{DERMOSCOPY}

\section{Diffuse alopecia}

Dermoscopy of the scalp has been increasingly used in medical practice in recent years. Several methods, including traditional dermatoscope, dermatoscope with polarized light, videodermatoscope with polarized light, and their association with a computerized analysis of hairs are available. Most dermatologists already use the traditional dermatoscope to examine pigmented lesions, and the findings on the scalp resulting from the use of this device are the most relevant. Traditionally performed with gel or oil, when used without immersion, dermoscopy may be useful for analyzing tertiary structures of the scalp such as vellus hair, irregularities, sweat pores, sebum secretion, and exudation. Dermoscopy can be used in evaluation or therapy follow-up, with an area being permanently marked with a small tattoo. One of the most evident aspects of dermoscopy on the scalp is the

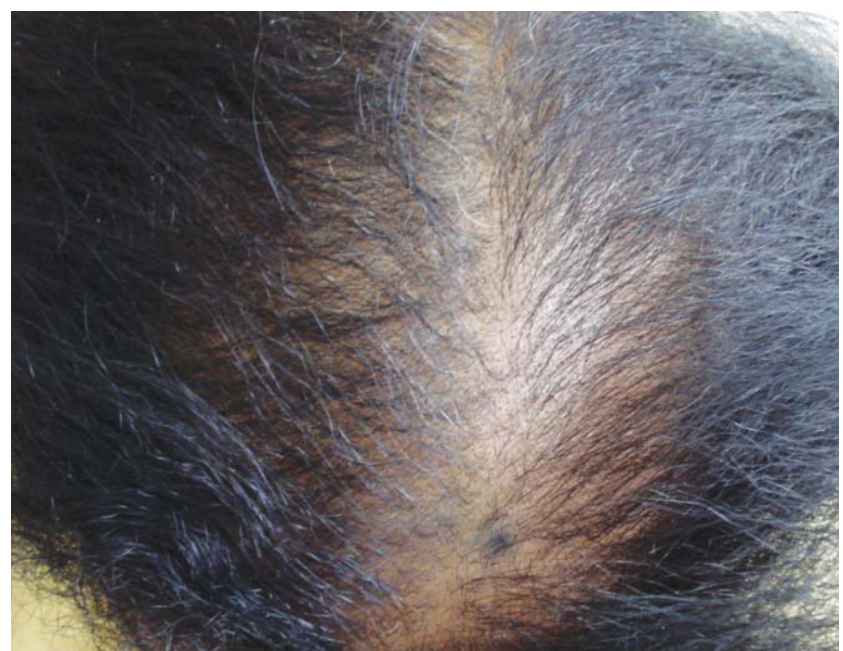

FIgURE 2: Female androgenetic alopecia. Clinical aspect with emphasis on preservation of the frontal hairline 
observation of hair diameter. Normal dermoscopic examination shows homogeneous diameters of the shafts and a normal pattern of vascularization of the scalp, with tree-like or circular vessels among follicular units with one to four shafts. ${ }^{23}$ Occasional visualization of thinner shafts is normal (histological parameter of normality is seven terminal hairs for each vellus hair). ${ }^{24-}$

${ }^{28}$ Skin pigmentation in a honeycomb pattern can be identified in patients with darker skin or in areas of sparse hair exposed to sunlight. Contrast with the pigment network allows us to observe white dots, which are correlated with the ducts of eccrine glands. ${ }^{29}$

\section{Female androgenetic alopecia}

Clinical findings are not easily perceptible in the initial phases of female androgenetic alopecia, and dermoscopy may reveal early changes. A variety of hair thickness is evident in the affected area, with a variation of more than $20 \%$ of the diameter of the shafts, usually in the central area of the scalp, corresponding to hair miniaturization. ${ }^{30}$ It is possible to compare hair density in the occipital area with hair density in the affected area, in an attempt to observe hair thinning. Peripilar signs, as a peri-follicular brown halo (Figure 3) or slight desquamation, can be observed without immersion. ${ }^{30}$ Seborrheic dermatitis may be associated with female androgenetic alopecia. Yellowish scales can be identified as well as an increase in circular vessels due to the inflammatory process. ${ }^{23}$

In high magnification (70x) dermoscopy, three major diagnostic criteria and three minor diagnostic criteria were proposed for female androgenetic alopecia. ${ }^{31}$ The major criteria were the following: more than four yellow dots in four fields in the frontal area, decreased average shaft thickness in the frontal area

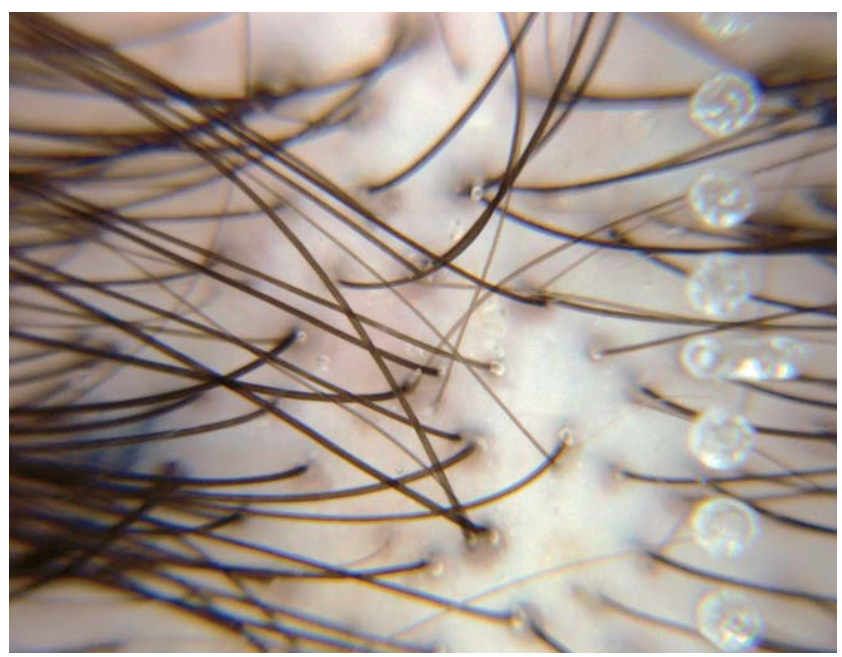

FIGURE 3: Dermoscopic aspects in diffuse alopecias. Variation of the diameter of the shafts and perifollicular hyperpigmentation in the crown in female androgenetic alopecia compared to the occipital scalp and more than $10 \%$ of thin hairs (thinner than $0.03 \mathrm{~mm}$ ) in the frontal area. Minor criteria included the following: perifollicular discoloration, increased single-hair pilosebaceous units in the frontal area compared to the occipital area, and increased vellus hairs in the frontal area compared to the occiput. Two major criteria and/or one major and one minor criterion reached a specificity of $98 \%$, when related to histopathology, in 59 cases. These findings highlight the differences between female androgenetic alopecia and telogen effluvium, but their practical application is still limited because most dermatologists use conventional dermoscopy, which does not allow for these changes to be easily identified.

\section{MICROSCOPIC FEATURES \\ Diffuse alopecia}

Scalp biopsy in diffuse alopecia is recommended when clinical and dermoscopic findings are inconclusive. Instructions on how to better obtain a sample of the scalp to investigate alopecia have been discussed elsewhere. ${ }^{32}$ Briefly, samples obtained with 4 to $6 \mathrm{~mm}$ punches that includes the hypodermis to access the bulbs of terminal follicles, and histological transverse sections to analyze the follicles globally, are essential to study cases of diffuse non-scarring alopecia. Recognizing normal qualitative and quantitative parameters of the scalp is critical to identify pathological changes, for a systematic analysis of histological transverse sections can provide sufficient data for the diagnosis.

The first step is to count the total number of follicles and identify the number of vellus, terminal and telogen hairs, telogen germinal units, and catagen hairs using multiple levels of histological sections from the superficial dermis to the hypodermis. The total number of follicles in a $4 \mathrm{~mm}$ punch may be between 19 and 59, due to individual variations, such as ethnicity (in the authors' experience, the average is between 30 and 35 follicles). ${ }^{24,33}$ By definition, vellus hairs have hair shaft diameter smaller than or equal to the thickness of the inner root sheath and are seen at the superficial dermis. ${ }^{24}$ The number of terminal hairs should be divided by the number of vellus hairs, defining the ratio terminal:vellus $(\mathrm{T}: \mathrm{V})$. In normal scalp, this ratio is $7: 1$ or more. ${ }^{24-28}$ Telogen count (TC) is obtained by dividing the number of telogen hairs (including catagen hairs and telogen germinal units) by the total number of terminal follicles (vellus hairs are not considered). Normally, this rate is around 6\% in $4 \mathrm{~mm}$ punch biopsies. ${ }^{24,25,27,28}$ In case of inflammation, it is important to observe intensity, location (perivascular, perifollicular or peribulbar) and composition (if there are cells other than lymphocytes). It is also useful to note the presence of trichomalacia. 
Finally, follicular fibrous tracts, which serve as "trail" for the hair cycle (also called streamers or stelae) should be examined in relation to their number and aspect, especially if there is an inflammatory component and melanophages nearby.

\section{Androgenetic alopecia}

The typical finding of androgenetic alopecia is a total number of follicles within the usual range, with a decrease in the ratio T:V, where the diagnostic rate is considered less than or equal to 4:1 (Figure 4). ${ }^{24-26,28,34}$ Over time, TC also increases. ${ }^{24-26,28,34}$ Another characteristic of the disease is noticeable variation between the diameters of the channels and terminal follicular shafts. ${ }^{24,25,28,34}$ Increased size of sebaceous glands is mentioned by some authors, although this parameter has not been critically assessed. ${ }^{34}$ Inflammation, when present, is predominantly lymphocytic and of mild intensity, usually around the superficial parts of the
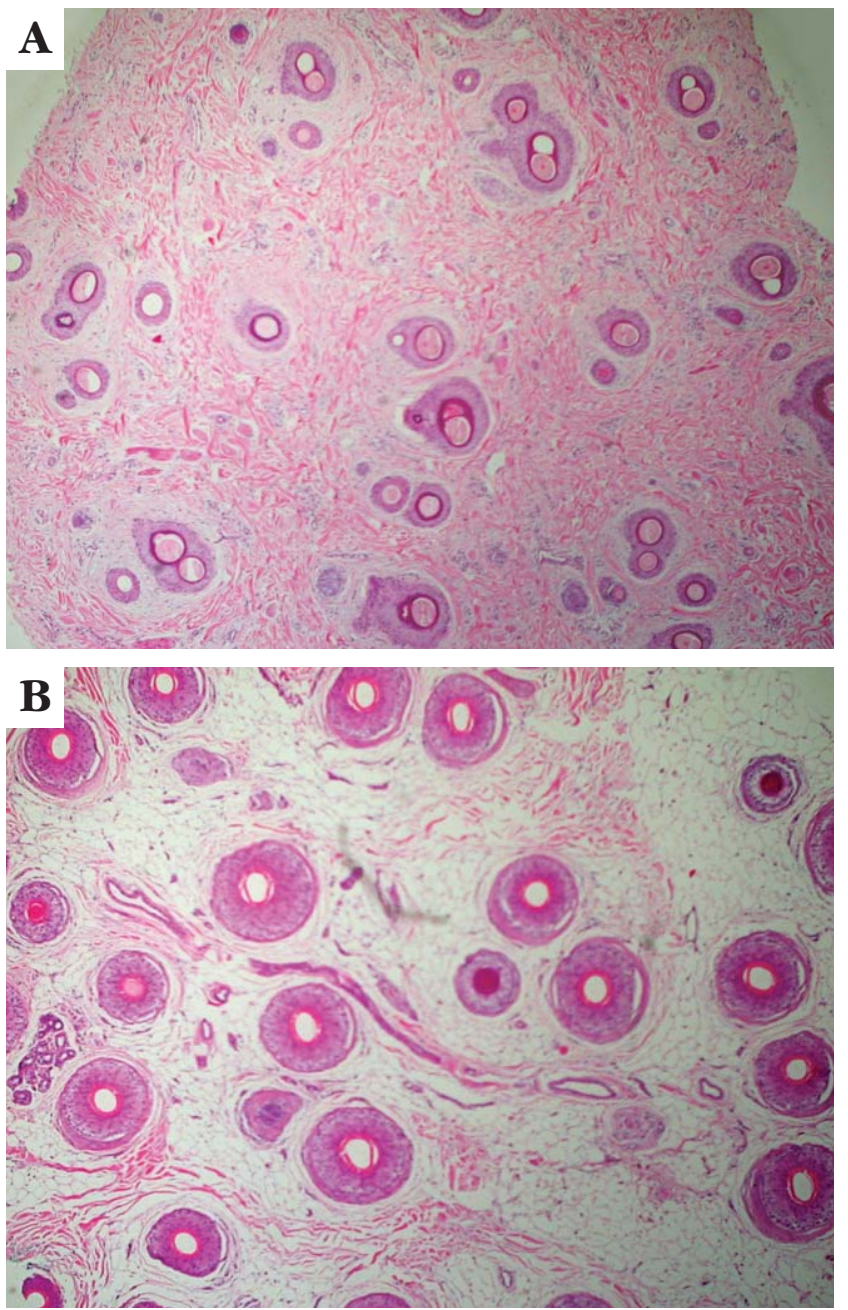

FIGURE 4: Histological transverse section of androgenetic alopecia A. Superficial dermis with approximately 60 follicles with visible variation in hair shaft diameter. B. Hypodermis with approximately 34 terminal hair follicles (T:V ratio of 1.3:1). HE, objective $\mathrm{x} 40$ follicle. ${ }^{25,34}$ Trichomalacia is not observed. As there is progressive miniaturization of follicles, the number of follicular fiber tracts also increases, and the more chronic the disease is, more hyalinized and less vascularized they become. ${ }^{24,25,34}$

Microscopic differential diagnosis between androgenetic alopecia in the initial phase and telogen effluvium can be difficult. Ekmekci, Sakiz and Koslu showed that $58 \%$ of all patients with androgenetic alopecia presented signs of alopecia in the occipital scalp, a fact that makes clinical differentiation with chronic telogen effluvium difficult. ${ }^{35}$ When biopsies from the patients' occipital scalp were analyzed, 25\% showed histological changes compatible with androgenetic alopecia. The most widely accepted histological parameter for differentiating the two diseases is the number of terminal hairs compared to the number of vellus hairs. The ratio $\mathrm{T}: \mathrm{V}<4: 1$ is characteristic of androgenetic alopecia (ratio $=$ or $<3: 1$ is considered conclusive) and the ratio $\mathrm{T}: \mathrm{V}>7: 1$ is indicative of chronic telogen effluvium. ${ }^{25,26,35-37}$ This means that $\mathrm{T}: \mathrm{V}$ values between 4:1 and 7:1 may not define the diagnosis. Furthermore, the number of telogen follicles and/or telogen germinal units may increase in both conditions, becoming one more complicating factor. However, as evidenced by Sinclair et al, these ratios are dependent on the sample, and multiple biopsies may be required to obtain the real values in each patient. ${ }^{26}$ In another article, Sinclair reported the case of a young woman with clinical and histological parameters of chronic telogen effluvium associated with thyroid disease who presented significant changes in the macro and microscopic characteristics of alopecia in a year, leading to the diagnosis of androgenetic alopecia. ${ }^{37}$ The author points out limitations in the sample (at the onset of symptoms, just one $4 \mathrm{~mm}$ punch biopsy was performed) as a possible cause for the initial misdiagnosis and emphasizes the real difficulty in differentiating between the two conditions.

\section{CONCLUSION}

Diffuse alopecia may present a diagnostic challenge when it is caused by female androgenetic alopecia, telogen effluvium, or diffuse alopecia areata. In female androgenetic alopecia, the main complaint is hair thinning. Also, lower hair density in the central portion of the scalp, with preservation of the frontal hairline, is perceptible on physical examination. The main dermoscopic criteria for the disease include more than four yellow dots in four sections of the frontal area, decreased average shaft thickness in the frontal area compared to the occipital area, and more than $10 \%$ of thin hairs in the frontal area. The most striking histological characteristic of the disease is the ratio $\mathrm{T}: \mathrm{V}<4: 1$. 


\section{REFERENCES}

1. Harrison S, Bergfeld W. Diffuse hair loss: its triggers and management. Cleve Clin J Med. 2009;76:361-7.

2. Santamaria JR, Spoladore R, Ribeiro AM. Alopecias - Alopecia difusa na mulher. An Bras Dermatol. 1992;87:195-7.

3. Rutowitsch MS, Antonio JR, Steiner D, Talarico S. Alopecia androgenética. An Bras Dermatol. 1999;74:561-72.

4. Mulinari-Brenner F, Bergfeld W. Entendendo o eflúvio telógeno. An Bras Dermatol. 2002;77:87-94

5. Rivitti EA. Alopecia areata: revisão e atualização. An Bras Dermatol. 2005;80:5768.

6. Pereira JM. Eflúvio telógeno após dermatite de contato no couro cabeludo. An Bras Dermatol. 2006;81(Suppl 3):S288-9.

7. García-Hernández MJ, Camacho FM. Chronic telogen effluvium: incidence, clinical and biochemical features, and treatment. Arch Dermatol. 1999;135:1123-4.

8. Harrison S, Sinclair R. Telogen effluvium. Clin Exp Dermatol. 2002;27:389-5.

9. Whiting DA. Chronic telogen effluvium: increased scalp hair shedding in middleaged women. J Am Acad Dermatol. 1996;35:899-906.

10. Birch MP, Lalla SC, Messenger AG. Female pattern hair loss. Clin Exp Dermatol. 2002;27:383-8

11. Papadopoulos AJ, Schwartz RA, Janniger CK. Alopecia areata. Pathogenesis, diagnosis, and therapy. Am J Clin Dermatol. 2000;1:101-5.

12. Gilhar A, Paus R, Kalish RS. Lymphocytes, neuropeptides, and genes involved in alopecia areata. J Clin Invest. 2007;117:2019-27.

13. Tosti A, Whiting D, lorizzo M, Pazzaglia M, Misciali C, Vincenzi C, et al. The role of scalp dermoscopy in the diagnosis of alopecia areata incognita. J Am Acad Dermatol. 2008:59:64-7.

14. Sato-Kawamura M, Aiba S, Tagami H. Acute diffuse and total alopecia of the female scalp. A new subtype of diffuse alopecia areata that has a favorable prognosis. Dermatology. 2002;205:367-73.

15. Olsen EA, Messenger AG, Shapiro J, Bergfeld WF, Hordinsky MK, Roberts JL, et al. Evaluation and treatment of male and female pattern hair loss. J Am Acad Dermatol. 2005;52:301-11

16. Olsen EA. The midline part: an important physical clue to the clinical diagnosis of androgenetic alopecia in women. J Am Acad Dermatol. 1999;40:106-9.

17. Cash TF. The psychosocial consequences of androgenetic alopecia: a review of the research literature. Br J Dermatol. 1999;141:398-405.

18. Gan DC, Sinclair RD. Prevalence of male and female pattern hair loss in Maryborough. Investig Dermatol Symp Proc. 2005;10:184-9.

19. Sawaya M, Price V. Different levels of 5alfa-reductase type I and II, aromatase, and androgen receptor in hair follicles of women and men with androgenetic alopecia. J Invest Dermatol. 1997:109:296-300.

20. Rebora A, Guarrera M. Kenogen. A new phase of the hair cycle? Dermatology. 2002;205:108-10.

21. Wiegratz I, Kuhl H. Managing cutaneous manifestations of hyperandrogenic disorders: the role of oral contraceptives. Treat Endocrinol. 2002;1:372-86.
22. Essah PA, Wickham EP 3rd, Nunley JR, Nestler JE. Dermatology of androgen-related disorders. Clin Dermatol. 2006;24:289-98.

23. Tosti A, Torres F. Dermoscopy in the diagnosis of hair and scalp disorders. Actas Dermosifiliogr. 2009;100 (Suppl 1):114-9.

24. Sperling LC. An atlas of hair pathology with clinical correlations. New York: The Parthenon Publishing Group; 2003.

25. Stefanato CM. Histopathology of alopecia: a clinicopathological approach to diagnosis. Histopathology. 2010;56:24-38.

26. Sinclair R, Jolley D, Mallari R, Magee J. The reliability of horizontally sectioned scalp biopsies in the diagnosis of chronic diffuse telogen hair loss in women. J Am Acad Dermatol. 2004;51:189-99.

27. Whiting DA. Histopathologic features of alopecia areata: a new look. Arch Dermatol. 2003;139:1555-9.

28. Whiting DA. Chronic telogen effluvium: increased scalp hair shedding in middleaged women. J Am Acad Dermatol. 1996;35:899-906.

29. Abraham LS, Piñeiro-Maceira J, Duque-Estrada B, Barcaui CB, Sodré CT. Pinpoint white dots in the scalp: dermoscopic and histopathologic correlation. J Am Acad Dermatol. 2010;63:721-2.

30. Inui S, Nakajima T, Itami S. Scalp dermoscopy of androgenetic alopecia in Asian people. J Dermatol. 2009;36:82-5.

31. Rakowska A, Slowinska M, Kowalska-Oledzka E, Olszewska M, Rudnicka L Dermoscopy in female androgenic alopecia: method standardization and diagnostic criteria. Int J Trichology. 2009;1:123-30.

32. Werner B. Biópsia de pele e seu estudo histológico. Por quê? Para quê? Como? Parte II. An Bras Dermatol. 2009;84:507-13.

33. Mulinari-Brenner F, Fillus Neto J, Torres LFB, Souza FHM. Avaliação quantitativa em cortes histológicos transversais do couro cabeludo. An Bras Dermatol. 2006;81 227-32.

34. Sellheyer K, Bergfeld WF. Histopathologic evaluation of alopecias. Am J Dermatopathol. 2006;28:236-59

35. Ekmekci TR, Sakiz D, Koslu A. Occipital involvement in female pattern hair loss histopathological evidences. J Eur Acad Dermatol Venereol. 2010;24:299-301.

36. Sinclair R. Chronic telogen effluvium: a study of 5 patients over 7 years. J Am Acad Dermatol. 2005:52(2 Suppl 1):12-6.

37. Sinclair R. Chronic telogen effluvium or early androgenetic alopecia? Int J Dermatol. 2004:43:842-3.

\author{
MAILING ADDRESS: \\ Betina Werner \\ Rua. Dr. Nelson de Souza Pinto, 759 \\ 82200-060 Curitiba, PR \\ E-mail address: betina.werner@gmail.com
}

How to cite this article: Werner B, Mulinari-Brenner F. Clinical and histological challenge in the differential diagnosis of diffuse alopecia: female androgenetic alopecia, telogen effluvium and alopecia areata - Part I. An Bras Dermatol. 2012;87(5):742-7. 